\title{
Is IDH status the only factor predicting prognosis in newly diagnosed anaplastic glioma patients? Outcome evaluation and prognostic factor analysis in a single-institution large series
}

\author{
Pierina Navarria, MD, ${ }^{1}$ Federico Pessina, MD, ${ }^{2,5}$ Elena Clerici, MD, ${ }^{1}$ Zefferino Rossini, MD, ${ }^{2}$ \\ Davide Franceschini, MD, ${ }^{1}$ Giuseppe D'Agostino, MD, ${ }^{1}$ Ciro Franzese, MD, ${ }^{1,5}$ Tiziana Comito, MD, ${ }^{1}$ \\ Mauro Loi, MD, ${ }^{1}$ Matteo Simonelli, MD, ${ }^{3,5}$ Elena Lorenzi, MD, ${ }^{3}$ Pasquale Persico, MD, ${ }^{3}$ \\ Letterio Salvatore Politi, MD, ${ }^{4,5}$ Marco Grimaldi, MD, ${ }^{4}$ Lorenzo Bello, MD, ${ }^{6}$ Armando Santoro, MD, ${ }^{3,5}$ \\ Maurizio Fornari, MD, ${ }^{2}$ Franco Servadei, MD, ${ }^{2,5}$ and Marta Scorsetti, MD ${ }^{1,5}$
}

\begin{abstract}
Departments of ${ }^{1}$ Radiotherapy and Radiosurgery, ${ }^{2}$ Neurosurgery, ${ }^{3}$ Oncology and Hematology, and ${ }^{4}$ Neuroradiology, Humanitas Cancer Center and Research Hospital, Rozzano; ${ }^{5}$ Department of Biomedical Sciences, Humanitas University, Rozzano; and ${ }^{6}$ Department of Oncology and Hemato-Oncology, Università degli Studi di Milano, Italy
\end{abstract}

\begin{abstract}
OBJECTIVE Anaplastic gliomas (AGs) are an extremely heterogeneous group of primary brain tumors. More recently, new discoveries have indicated that isocitrate dehydrogenase (IDH) mutation status is the most important parameter predicting survival. The primary aim of the present analysis was to identify prognostic factors, other than IDH status, that eventually impact survival.
\end{abstract}

METHODS Patients with available clinical, imaging, and molecular profile data who were amenable to resection were evaluated. The extent of resection (EOR) was defined as gross-total resection (GTR), near-total resection (NTR), subtotal resection (STR), or partial resection (PR). Residual tumor volume (RTV) was quantified. Following surgery, patients received adjuvant chemotherapy alone, radiation therapy plus concomitant and adjuvant temozolomide (TMZ), or sequential radio-chemotherapy. Clinical outcome was evaluated by neurological examination and MRI 1 month after treatment and every 4 months thereafter. Tumor progression was defined according to the Response Assessment in Neuro-Oncology (RANO) working group.

RESULTS Among 402 patients referred to the authors' institution for AG, 142 were included in the present analysis. Eighty-eight (62\%) were male and 54 (38\%) were female, with a median age of 43 years (range 19-70 years). At admission, most patients had a Karnofsky Performance Scale score of 90-100 (84.5\%) and were symptomatic (93.7\%). Fortyeight (33.8\%) patients had newly diagnosed anaplastic oligodendrogliomas (AOs), and 94 (66.2\%) had anaplastic astrocytomas (AAs). Most of them had mutant IDH tumors (67.6\%) and methylated $0^{6}$-methylguanine-DNA-methyltransferase (MGMT) promoter status (71.8\%). GTR was performed in more than half of the patients (56.3\%). RTV was detected in 83 (58.5\%) patients. Following surgery, $72(50.7 \%)$ patients received radiotherapy with concomitant and adjuvant TMZ, 48 (33.8\%) received sequential radio-chemotherapy, and $22(15.5 \%)$ received adjuvant chemotherapy alone. The median follow-up time was 40 months (range 16-146 months). The median PFS time and the 1-, 3-, and 5-year PFS rates were 35 months $(95 \% \mathrm{Cl} 27-76)$ and $78.9 \% \pm 3.4 \%, 49.7 \% \pm 4.6 \%$, and $42.7 \% \pm 5.4 \%$, respectively. The median OS time and the 1-, 3-, and 5-year OS rates were 91 months $(95 \% \mathrm{Cl} 66-95)$ and $90.1 \% \pm 2.5 \%, 70.9 \% \pm 4.2 \%$, and $61.8 \% \pm 4.9 \%$, respectively. Prognostic factors predicting survival other than molecular profile were the EOR and the RTV $(p<0.0001)$. Sequential radio-chemotherapy was the more effective treatment administered.

\footnotetext{
ABBREVIATIONS $\mathrm{AA}=$ anaplastic astrocytoma; $\mathrm{AG}=$ anaplastic glioma; $\mathrm{AO}=$ anaplastic oligodendroglioma; $\mathrm{AOA}=$ anaplastic oligoastrocytoma; $\mathrm{CE}=\mathrm{contrast}$-enhanced; EOR = extent of resection; EORTC = European Organisation for Research and Treatment of Cancer; GBM = glioblastoma; GTR = gross-total resection; IDH = isocitrate dehydrogenase; KPS = Karnofsky Performance Scale; MGMT = 06-methylguanine-DNA-methyltransferase; NR = not reached; NTR = near-total resection; OS = overall survival; PCV = procarbazine, lomustine, and vincristine; PFS = progression-free survival; PR = partial resection; RTOG = Radiation Therapy Oncology Group; RTV = residual tumor volume; STR = subtotal resection; TMZ = temozolomide.
}

SUBMITTED April 6, 2020. ACCEPTED May 21, 2020

INCLUDE WHEN CITING Published online September 4, 2020; DOI: 10.3171/2020.5.JNS201116. 
CONCLUSIONS In addition to IDH status, EOR and the RTV have proved to statistically impact survival. The pivotal role of adjuvant radiotherapy has been recorded in all AG patients, regardless of tumor features.

https://thejns.org/doi/abs/10.3171/2020.5.JNS201116

KEYWORDS anaplastic glioma; prognostic factors; surgery; radiation therapy; chemotherapy; oncology

A NAPLASTIC gliomas (AGs) are an extremely heterogeneous group of primary brain tumors. In the last decade, comprehensive and integrative genomic and molecular analyses led to identification of biological classes with clinically distinct behavior: this resulted in a more accurate patient prognostic stratification, defined by molecular status rather than histological features. ${ }^{1}$ Before 2008, prominent molecular biomarkers were the $O^{6}$-methylguanine-DNA-methyltransferase (MGMT) promoter and 1p/19q codeletion. MGMT gene promoter methylation was found to be a predictive biomarker for increased activity of temozolomide (TMZ)., ${ }^{2,3}$ Likewise, $1 \mathrm{p} / 19 \mathrm{q}$ codeletion was identified as an important prognostic biomarker correlated with longer survival., ${ }^{4,5}$

The treatment strategies have been profoundly conditioned by these findings. Since the early 1990s, standard therapy for newly diagnosed anaplastic oligodendrogliomas (AOs) has been procarbazine, lomustine, and vincristine (PCV), with or without radiotherapy. ${ }^{6}$ Further advances in the management of AGs were provided by evidence from two prospective studies: the Radiation Therapy Oncology Group study (RTOG 9402), comparing radiotherapy with and without prior chemotherapy using PCV, and the European Organisation for Research and Treatment of Cancer study (EORTC 26951), testing radiotherapy with and without adjuvant PCV in patients. ${ }^{7,8}$ Both trials showed improved progression-free survival (PFS) without significant differences in overall survival (OS) in patients receiving radio-chemotherapy, though at the expense of increased incidence and severity of toxicity correlated to sequential administration of PCV. Subsequently, the NOA-04 trial compared the efficacy and safety of radiotherapy versus chemotherapy with either PCV or TMZ as an upfront therapy in patients with newly diagnosed supratentorial AGs and assessed the clinical relevance of 1p/19q codeletion and MGMT promoter methylation in response to treatment. ${ }^{9}$ Although preliminary analysis of NOA-04 showed comparable results of chemotherapy and radiotherapy, a long-term follow-up study reported a superior outcome in patients receiving initial radiotherapy compared with those receiving chemotherapy, hence confirming the role of adjuvant radiotherapy in AG. ${ }^{10}$

More recently, isocitrate dehydrogenase (IDH) mutation status showed a stronger correlation with biological behavior than $1 \mathrm{p} / 19 \mathrm{q}$ codeletion and MGMT methylation. $^{7-9}$ Based on comprehensive and integrative genomic analysis, three prognostic tumor classes have been identified: class I, IDH-mutant and 1p/19q-codeleted tumors; class II, IDH-mutant and 1p/19q-noncodeleted tumors; and class III, IDH wild-type tumors. ${ }^{11-16}$ These findings resulted in an update of the CNS WHO classification, in which different glioma entities have been introduced according to molecular parameters. ${ }^{17}$ The definition of these new entities is contributing to the change of current para- digms of treatment and allowing for tailored strategies based on expected biological aggressiveness and responsiveness to treatment. For instance, considering the poor outcomes associated with this condition, the CATNON trial (EORTC 26053-22054) evaluated the role of radiotherapy with concurrent and adjuvant TMZ compared with radiotherapy alone in patients affected by noncodeleted AG: the initial planned interim analysis showed a superior outcome in patients receiving adjuvant TMZ. ${ }^{18}$ The second interim and first molecular analysis, presented at ASCO 2019, suggested no benefit of concurrent chemotherapy on survival in the entire population, no benefit of concurrent and adjuvant chemotherapy in anaplastic astrocytoma (AA) IDH wild type, and a nonsignificant trend in favor of concomitant and adjuvant TMZ in IDH-mutant AA. Based on these data, it may be suggested that, in addition to IDH, other factors should be considered in guiding therapeutic choice. To date, few data are available in light of this new scenario, particularly assessing the role of other prognostic factors as well as molecular features. In addition, no conclusive evidence exists about the optimal therapeutic strategies for AGs and the impact of the amount of resection-widely evaluated in low-grade glioma or glioblastoma (GBM). Hence, we reviewed data of newly diagnosed AG patients treated at our institution who were classified according to the new WHO 2016 CNS classification. The primary aim was to identify prognostic factors, other than IDH status, eventually having an impact on outcome.

\section{Methods \\ Patients}

All patients were treated in accordance with the precepts of the Helsinki Declaration and provided written informed consent for the treatment and the use of their data for scientific purposes. Eligible patients had 1) newly diagnosed AGs; 2) available clinical and imaging data; 3) a visible and measurable tumor mass on volumetric postcontrast T1-weighted and FLAIR MR images; 4) an available molecular profile; 5) a tumor amenable to resection; and 6) adequate follow-up.

\section{Procedures}

\section{Surgery}

Surgery was performed in all patients with the aim of maximally removing the tumor mass according to functional boundaries, with the aid of imaging and brain mapping techniques. Neurophysiological monitoring included simultaneous acquisition of continuous electroencephalography, electrocorticography, multichannel recording of free-running electromyography activity, and motor evoked potentials (Comet EEG system, Grass Astro-Med, ISIS-IOM, and Inomed $\mathrm{GmbH}$, respectively). Tumor bor- 
ders were defined intraoperatively by neuronavigation coupled with ultrasound. Mapping of eloquent language and motor cortex (when needed) was performed to define the cortical safe-entry zone. Subcortical brain mapping (when requested) was then continued, along with tumor resection. The extent of resection (EOR) was determined by comparing preoperative MRI abnormalities, including postcontrast T1-weighted tumor and FLAIR signal, with postoperative MRI findings, acquired within 48 hours after surgery, and calculated as follows: (preoperative tumor volume - postoperative tumor volume)/preoperative tumor volume. According to Sanai and Berger, the EOR was defined as follows: gross-total resection (GTR), removal between $91 \%$ and 100\%; near-total resection (NTR), removal between $81 \%$ and $90 \%$; subtotal resection (STR), removal between $71 \%$ and $80 \%$; partial resection (PR), removal $\leq 70 \%$; and biopsy. ${ }^{19}$

The residual tumor volume (RTV) was measured on postoperative volumetric MR images acquired using a 3-Tesla scanner (Siemens) 48 hours after surgery through a semiautomatic region of interest analysis with iPlan Cranial v3.0 software (Brainlab). Postoperative MRI was coregistered with the preoperative data set. Three independent physicians with expertise in neurooncology performed the measurements. Contrast-enhanced (CE) T1-weighted sequences were used for volume calculation of the contrast enhancement component (if present) in the preoperative stage, while FLAIR sequences were used for volume calculation of the FLAIR abnormality component (with or without the presence of preoperative enhancement). The sum of volumes obtained by the two sequences was defined as the total preoperative volume. The same sequences were employed in the postoperative setting, defining CE RTV and FLAIR RTV. Postoperative diffusion-weighted imaging was also coregistered to rule out postoperative ischemic injury. The RTV was evaluated and defined as: RTV $0 \mathrm{~cm}^{3}$, RTV between 0.1 and $3 \mathrm{~cm}^{3}$, RTV between 3.1 and $10 \mathrm{~cm}^{3}$, and RTV > 10 $\mathrm{cm}^{3}$. RTV was defined as any residual MRI abnormality on postoperative MRI that was evident in the preoperative study. In particular, CE MRI was used to assess CE residual masses (CE RTV), and FLAIR MRI was used to measure unenhanced residual masses (FLAIR RTV). The sum of CE RTV and FLAIR RTV was recorded for lesions characterized by both tissue components and defined as total RTV. The presence of nonspecific enhancements due to blood deposition, choroid plexus, or vessels was identified and excluded. The tumor molecular profile was available in all cases. Immunohistochemical staining for isocitrate dehydrogenase (IDH1/2) was performed on a BenchMark XT automated tissue staining system (Ventana Medical Systems, Inc.) using validated protocols. The standard method of dual-color fluorescence in situ hybridization (FISH) performed on 4- $\mu$ m-thick paraffin sections was used to determine the $1 \mathrm{p} / 19 \mathrm{q}$ deletion status (Vysis probes 1p36/1q25 and 19q13/19p13). The presence of $1 p / 19 q$ codeletion defined AO tumors, and its absence, AA. MGMT promoter methylation status was determined by pyrosequencing (Diatech Pharmacogenetics, MGMT plus, valid European CE marking for in vitro diagnostic medical device).
TABLE 1. Patients and tumor characteristics

\begin{tabular}{lc}
\hline & Value \\
\hline No. of patients & 142 \\
\hline Sex & \\
Female & $54(38)$ \\
Male & $88(62)$ \\
\hline Median age, yrs (range) & $43(19-70)$ \\
\hline KPS score & \\
80 & $22(15.5)$ \\
90-100 & $120(84.5)$ \\
\hline Histology of AG & \\
AO & $48(33.8)$ \\
AA & $94(66.2)$ \\
\hline IDH1/2 status for entire cohort & \\
Mutant & $96(67.6)$ \\
Wild type & $46(32.4)$ \\
\hline MGMT status for entire cohort & \\
Methylated & $102(71.8)$ \\
Unmethylated & $40(28.2)$ \\
\hline IDH/MGMT status for AO & $48(33.8)$ \\
IDH mutant & $42(87.5)$ \\
IDH wild type & $6(12.5)$ \\
MGMT methylated & $41(85.4)$ \\
MGMT unmethylated & $7(14.6)$ \\
IDH/MGMT status for AA & $94(66.2)$ \\
IDH mutant & $54(57.4)$ \\
IDH wild type & $40(42.6)$ \\
MGMT methylated & $61(64.9)$ \\
MGMT unmethylated & $30(32)$ \\
Histomolecular subgroup & $42(29.6)$ \\
IDH-mutant 1p/19q-codeleted tumor & $54(38.0)$ \\
IDH-mutant 1p/19q-noncodeleted tumor & $46(32.4)$ \\
IDH wild-type tumor & \\
\hline
\end{tabular}

Values are presented as the number of patients (\%) unless otherwise indicated.

\section{Adjuvant Treatment}

Adjuvant treatment consisted of adjuvant TMZ alone for younger patients with AO methylated MGMT tumors, who had undergone GTR without RTV; radiation therapy with concurrent and adjuvant TMZ for AA methylated MGMT, IDH wild-type tumors; or adjuvant radiotherapy followed by TMZ for the others.

\section{Radiation Therapy}

For patients receiving radiotherapy, CT scanning, T1weighted FLAIR, and T2-weighted 3D-FLAIR followed by T1-weighted MPRAGE MRI were performed for radiation therapy planning, and images were coregistered to each other. Preoperative and postoperative MRI scans acquired within 48 hours after surgery were used to better define the target radiotherapy volume. The clinical target volume corresponded to the entire surgical cavity plus eventual residual tumor after surgery and the abnormality on FLAIR MRI images after surgery. The planning target volume was generated, adding an isotropic margin of 5 $\mathrm{mm}$ from the clinical target volume. Intensity-modulated 


\begin{tabular}{|c|c|c|c|c|c|c|}
\hline & Entire Cohort & $\mathrm{AO}$ & AA & $\begin{array}{l}\text { IDH-Mutant } \\
\text { 1p/19q-Codel } \\
\text { Tumor }\end{array}$ & $\begin{array}{c}\text { IDH-Mutant } \\
\text { 1p/19q-Noncodel } \\
\text { Tumor }\end{array}$ & $\begin{array}{l}\text { IDH Wild-Type } \\
\text { Tumor }\end{array}$ \\
\hline No. of patients (\%) & $142(100)$ & $48(33.8)$ & $94(66.2)$ & $42(29.6)$ & $54(38)$ & $46(32.4)$ \\
\hline \multicolumn{7}{|l|}{ EOR } \\
\hline GTR & $80(56.3)$ & $35(72.9)$ & $45(47.9)$ & $31(73.8)$ & $25(46.3)$ & $24(52.3)$ \\
\hline NTR & $14(9.9)$ & $6(12.5)$ & $8(8.5)$ & $6(14.3)$ & $6(11.1)$ & $2(4.3)$ \\
\hline STR & $13(9.2)$ & $3(6.2)$ & $10(10.6)$ & $3(7.1)$ & $8(14.8)$ & $2(4.3)$ \\
\hline $\mathrm{PR} / \mathrm{B}$ & $35(24.6)$ & $4(8.3)$ & $31(33)$ & $2(4.8)$ & $15(27.8)$ & $18(39.1)$ \\
\hline \multicolumn{7}{|l|}{ Presence of RTV } \\
\hline Yes & $83(58.5)$ & $22(45.8)$ & $61(64.9)$ & $18(42.9)$ & $34(63)$ & $31(67.4)$ \\
\hline No & $59(41.5)$ & $26(54.2)$ & $33(35.1)$ & $24(57.1)$ & $20(37)$ & $15(32.6)$ \\
\hline Median total, $\mathrm{cm}^{3}$ (range) & $10.83(0.16-119.8)$ & $5.5(0.16-67.3)$ & $12.81(0.3-119.8)$ & $5.6(0.19-67.32)$ & $12.62(0.3-119.8)$ & $50(0.16-93.54)$ \\
\hline Presence of FLAIR RTV only & 55 & 17 & 38 & 18 & 27 & 13 \\
\hline Median, $\mathrm{cm}^{3}$ (range) & $10.53(0.16-12.4)$ & $5.5(0.16-67.3)$ & $10.53(0.3-93.5)$ & $5.6(0.19-67.3)$ & $11.2(0.3-77.2)$ & $4.06(0.16-93.5)$ \\
\hline \multicolumn{7}{|l|}{ Amount of FLAIR RTV only* } \\
\hline $0.1-3 \mathrm{~cm}^{3}$ & $13(23.6)$ & $6(35.3)$ & 7 (18.4) & $5(27.8)$ & $5(18.5)$ & $4(30.8)$ \\
\hline $3.1-10 \mathrm{~cm}^{3}$ & $19(34.5)$ & $8(47.1)$ & $11(28.9)$ & $9(50)$ & $6(22.2)$ & $5(38.5)$ \\
\hline$>10 \mathrm{~cm}^{3}$ & $23(41.8)$ & $3(17.6)$ & $20(52.6)$ & $4(22.2)$ & $16(59.3)$ & $4(30.8)$ \\
\hline $\begin{array}{l}\text { Presence of CE RTV only } \\
\text { Median, } \mathrm{cm}^{3} \text { (range) }\end{array}$ & $\begin{array}{c}3 \\
0.9(0.7-0.9)\end{array}$ & 0 & $\begin{array}{c}3 \\
0.9(0.7-0.9)\end{array}$ & 0 & $\begin{array}{c}1 \\
(0.9)\end{array}$ & $\begin{array}{c}2 \\
(0.7 \& 0.9)\end{array}$ \\
\hline \multicolumn{7}{|l|}{ Amount of CE RTV only* } \\
\hline $0.1-3 \mathrm{~cm}^{3}$ & $3(100)$ & $0(0)$ & $3(100)$ & $0(0)$ & $0(100)$ & $2(100)$ \\
\hline $3.1-10 \mathrm{~cm}^{3}$ & $0(0)$ & $0(0)$ & $0(0)$ & $0(0)$ & $0(0)$ & $0(0)$ \\
\hline$>10 \mathrm{~cm}^{3}$ & $0(0)$ & $0(0)$ & $0(0)$ & $0(0)$ & $0(0)$ & $0(0)$ \\
\hline Presence of FLAIR RTV+CE RTV & 25 & 5 & 20 & 3 & 6 & 16 \\
\hline Median, $\mathrm{cm}^{3}$ (range) & $5.78(0.16-118.9)$ & $12.38(5.4-50)$ & $50(0.7-119.8)$ & $10.8(5.4-12.4)$ & $50(3.7-119.8)$ & $50(3.2-50)$ \\
\hline \multicolumn{7}{|l|}{ Amount of FLAIR RTV+CE RTV* } \\
\hline $0.1-3 \mathrm{~cm}^{3}$ & $0(0)$ & $0(0)$ & $0(0)$ & $0(0)$ & $0(0)$ & $0(0)$ \\
\hline $3.1-10 \mathrm{~cm}^{3}$ & $3(12)$ & $1(20)$ & $2(10)$ & $1(33.3)$ & $1(16.7)$ & $1(6.2)$ \\
\hline$>10 \mathrm{~cm}^{3}$ & $22(88)$ & $4(80)$ & $18(90)$ & $2(66.7)$ & $5(83.3)$ & $15(93.8)$ \\
\hline \multicolumn{7}{|l|}{ Adjuvant treatment } \\
\hline TMZ & $22(15.5)$ & $13(27.1)$ & $9(9.6)$ & $12(28.6)$ & $6(11.1)$ & $4(8.7)$ \\
\hline RT+cTMZ \& adjuvant aTMZ & $72(50.7)$ & $21(43.8)$ & $51(54.3)$ & $18(42.9)$ & $22(40.7)$ & $32(69.6)$ \\
\hline $\mathrm{RT}+\mathrm{aTMZ}$ & $48(33.8)$ & $14(29.2)$ & $34(36.2)$ & $12(28.6)$ & $26(48.2)$ & $10(21.7)$ \\
\hline
\end{tabular}

aTMZ = adjuvant TMZ; B = biopsy; Codel = codelete; $\mathrm{CTMZ} \mathrm{=} \mathrm{concomitant} \mathrm{TMZ;} \mathrm{Noncodel} \mathrm{=} \mathrm{noncodelete;} \mathrm{RT} \mathrm{=} \mathrm{radiotherapy.}$

Values are presented as the number of patients (\%) unless otherwise indicated.

${ }^{*}$ Percentages are based on the number of patients meeting the criterion.

radiation therapy was performed within 4-6 weeks after surgery using volumetric modulated arc therapy. The dose prescribed was $60 \mathrm{~Gy}$ with a daily fraction of 2 Gy to the planning target volume. Dose was prescribed to an isodose line that ensured that more than $98 \%$ of the planning target volume receives $95 \%$ of the prescribed dose. Organs at risk outlined were optic nerves and chiasm, lens, brainstem, and cochlea without additional margins. In each session, a patient-position check was performed using the ExacTrac (Brainlab) system and cone-beam CT.

\section{Chemotherapy}

Chemotherapy consisted of TMZ administered at 75 $\mathrm{mg} / \mathrm{m}^{2}$ in the concomitant setting starting on the 1 st day of radiotherapy and continuing for the entire treatment. In the adjuvant setting, TMZ was administered at 150 to $200 \mathrm{mg} / \mathrm{m}^{2}$ orally, once daily, for 5 consecutive days ev- ery 28 days up to 12 cycles, or until disease progression occurred.

\section{Outcome Evaluation}

Clinical outcome was evaluated by neurological examination and MRI 1 month after treatment and every 4 months thereafter. When needed, tumor progression was defined according to the Response Assessment in NeuroOncology (RANO) working group..$^{20}$

\section{Statistical Analysis}

Standard descriptive statistics (mean, standard deviation, and cross-tabulation analysis) were used to describe the general behavior of the data. The median survival time was obtained from $\hat{S}(\mathrm{t})$, the Kaplan-Meier product-limit estimate of the survivor function. A not-reached (NR) in- 


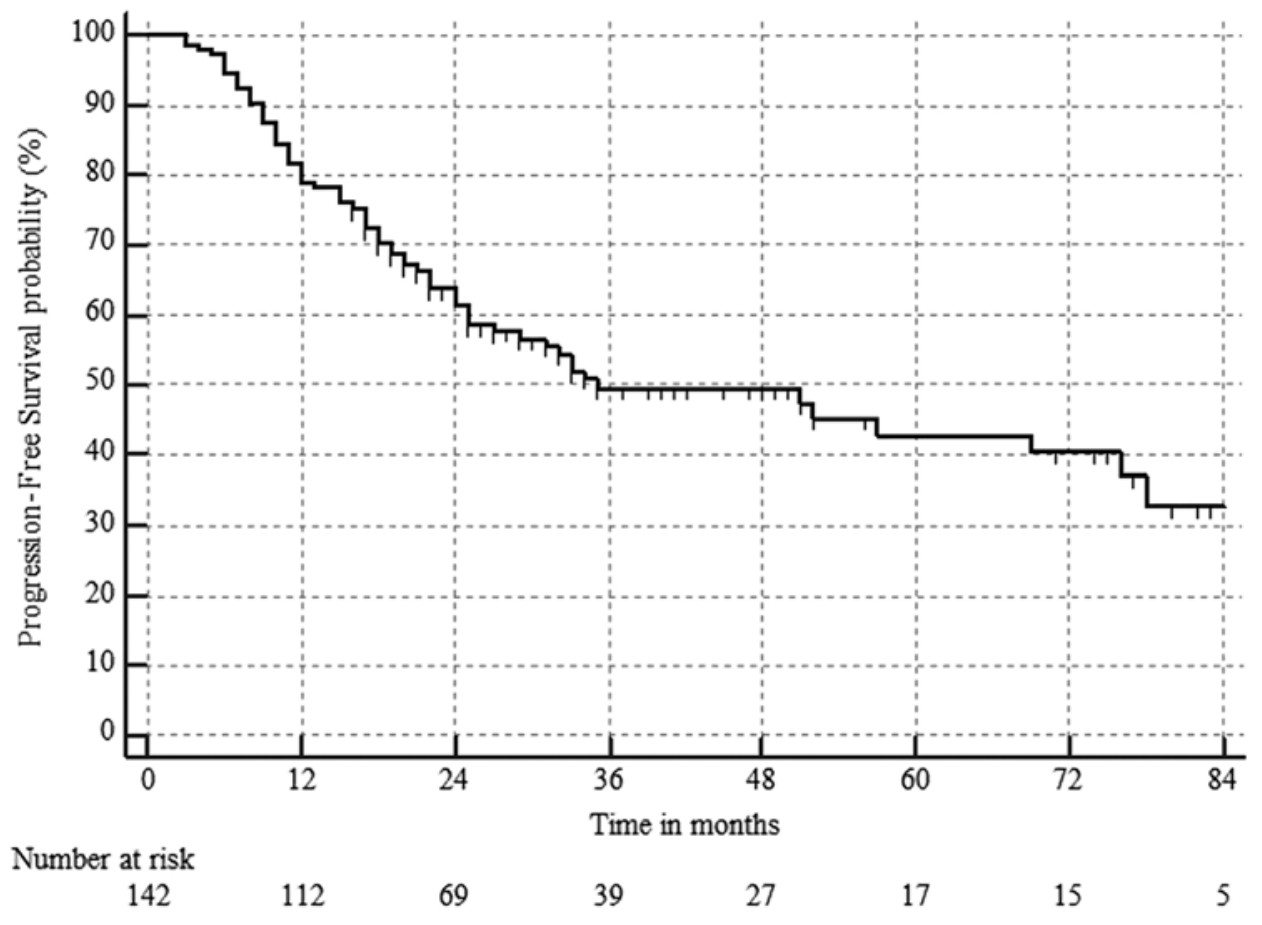

FIG. 1. PFS of newly diagnosed $A G$ patients.

dicator was specified if the resulting survival estimate was above the $50 \%$ level in the considered observation time. The upper confidence bound of median survival time was labeled as NR if it was not evaluable with the aforementioned method for a specific group of patients in the considered time of observation. PFS and OS rates were calculated from the time of primary diagnosis. To assess the prognostic role of the different individual variables, the log-rank test was used for the variables sex; age (median); Karnofsky Performance Scale (KPS) score (80 or 90100); EOR (GTR, NTR, STR, PR, or biopsy); total, CE, and FLAIR RTV after surgery; glioma histology; IDH status; MGMT status; histomolecular subgroups (IDHmutant 1p/19q-codeleted tumors; IDH-mutant 1p/19qnoncodeleted tumors; and IDH wild-type tumors); and the different adjuvant treatments performed. The univariate Cox model was applied for the remaining variables. The multivariate Cox regression model was used as a method to estimate the independent association of our variable set with PFS and OS. Multivariate analysis was restricted to variables for which a significant correlation with outcome was shown using a threshold of $\mathrm{p} \leq 0.05$. Statistical analysis was performed using MedCalc software, v17.7.

\section{Results}

\section{Patients}

From January 2008 to November 2018, among 402 patients referred to our institution for AGs, 142 with complete clinical, radiological, histopathological, and molecular profile data were included in the present analysis. Eighty-eight (62\%) patients were male and 54 (38\%) were female, with a median age of 43 years (range 19-70 years). At admission, most patients $(84.5 \%)$ had a KPS score of $90-100$ and were symptomatic (93.7\%). Fortyeight (33.8\%) patients had newly diagnosed AOs, and 94 (66.2\%) had AAs. Most patients had IDH-mutant tumors (67.6\%) and methylated MGMT promoter status (71.8\%). Table 1 shows patient and tumor characteristics. Resection was performed in all patients, with GTR achieved in more than half of the patients $(56.3 \%)$. RTV was detected in $83(58.5 \%)$ patients. The median total RTV, including CE RTV and/or FLAIR RTV, was $10.83 \mathrm{~cm}^{3}$ (range $0.16-$ $119.77 \mathrm{~cm}^{3}$ ), the median CE RTV was $5.78 \mathrm{~cm}^{3}$ (range $\left.0.16-118.90 \mathrm{~cm}^{3}\right)$, and the median FLAIR RTV was 10.53 $\mathrm{cm}^{3}$ (range $0.16-12.38 \mathrm{~cm}^{3}$ ). Following surgery, 72 (50.7\%) patients received radiotherapy with concomitant and adjuvant TMZ, 48 (33.8\%) received sequential radio-chemotherapy, and $22(15.5 \%)$ received adjuvant chemotherapy alone. Details about treatment characteristics are shown in Table 2.

\section{PFS and OS Analyses}

The median follow-up time was 40 months (range 16146 months) from a primary diagnosis of AG. For the entire cohort, the median PFS time was 35 months $(95 \%$ CI 27-76), and the 1-, 3-, and 5-year PFS rates were 78.9\% \pm $3.4 \%, 49.7 \% \pm 4.6 \%$, and $42.7 \% \pm 5.4 \%$, respectively (Fig. 1 and Table 3). The median OS time was 91 months (95\% CI 66-95), and the 1-, 3-, and 5-year OS rates were 90.1\% $\pm 2.5 \%, 70.9 \% \pm 4.2 \%$, and $61.8 \% \pm 4.9 \%$, respectively (Fig. 2 and Table 4).

For AO patients, the median PFS time was 78 months (95\% CI 32-89), and the 1-, 3-, and 5-year PFS rates were $89.6 \% \pm 4.4 \%, 64.5 \% \pm 7.5 \%$, and $64.5 \% \pm 7.5 \%$, respec- 


\begin{tabular}{|c|c|c|c|c|c|c|c|}
\hline & \multirow{2}{*}{$\begin{array}{c}\text { No. of } \\
\text { Patients }\end{array}$} & \multirow{2}{*}{$\begin{array}{l}\text { Median } \\
\text { PFS, Mos } \\
\text { (range) }\end{array}$} & \multicolumn{2}{|c|}{ Mean \pm SD } & \multirow{2}{*}{$\begin{array}{c}\text { Univariate } \\
\text { p Value }\end{array}$} & \multirow{2}{*}{$\begin{array}{c}\text { Multivariate HR } \\
\quad(95 \% \mathrm{Cl})\end{array}$} & \multirow{2}{*}{$\begin{array}{c}\text { Multivariate } \\
\text { p Value }\end{array}$} \\
\hline & & & 3-Yr PFS, \% & 5-Yr PFS, \% & & & \\
\hline PFS & 142 & $35(27-76)$ & $49.7 \pm 4.6$ & $42.7 \pm 5.4$ & & & \\
\hline Sex & & & & & 0.4 & & \\
\hline Female & 54 & $52(32-89)$ & $57.4 \pm 7.6$ & $38.3 \pm 10.4$ & & & \\
\hline Male & 88 & $31(22-76)$ & $45.2 \pm 5.8$ & $45.2 \pm 5.8$ & & & \\
\hline Age, yrs & & & & & 0.06 & & \\
\hline$\leq 43$ & 75 & $57(33-78)$ & $58.4 \pm 6.4$ & $47.8 \pm 7.6$ & & & \\
\hline$>43$ & 67 & $25(19-89)$ & $40.0 \pm 6.6$ & $40.0 \pm 6.6$ & & & \\
\hline KPS score & & & & & 0.53 & & \\
\hline $90-100$ & 120 & $51(27-78)$ & $51.6 \pm 5.0$ & $43.4 \pm 6.0$ & & & \\
\hline 80 & 22 & 31 (12-35) & $39.2 \pm 11.9$ & $39.2 \pm 11.9$ & & & \\
\hline EOR & & & & & 0.0009 & $1.23(1.01-1.51)$ & 0.03 \\
\hline GTR & 80 & $78(33-78)$ & $59.5 \pm 6.2$ & $59.5 \pm 6.2$ & & & \\
\hline NTR & 14 & $35(18-35)$ & $45.9 \pm 14.3$ & $45.9 \pm 14.3$ & & & \\
\hline STR & 13 & $34(21-69)$ & $46.4 \pm 15.6$ & $30.9 \pm 16.4$ & & & \\
\hline PR/B & 35 & $15(11-32)$ & $31.9 \pm 8.2$ & $10.6 \pm 9.1$ & & & \\
\hline Total RTV & & & & & 0.005 & & \\
\hline No & 59 & 76 (33-78) & $63.2 \pm 7.2$ & $63.2 \pm 7.2$ & & & \\
\hline Yes & 83 & $25(18-51)$ & $40.7 \pm 5.8$ & $32 \pm 6.3$ & & & \\
\hline CE RTV & & & & & $<0.0001$ & & \\
\hline No & 114 & $52(33-89)$ & $55 \pm 5.4$ & $46.1 \pm 6.5$ & & & \\
\hline Yes & 28 & $12(11-18)$ & $25 \pm 8.1$ & $25 \pm 8.1$ & & & \\
\hline FLAIR RTV & & & & & 0.0088 & & \\
\hline No & 62 & $76(33-78)$ & $61.9 \pm 7.0$ & $61.9 \pm 7.0$ & & & \\
\hline Yes & 80 & $25(18-51)$ & $44.5 \pm 5.8$ & $31.4 \pm 6.6$ & & & \\
\hline Histology & & & & & 0.0077 & & \\
\hline $\mathrm{AO}$ & 48 & $78(32-89)$ & $64.5 \pm 7.5$ & $64.5 \pm 7.5$ & & & \\
\hline $\mathrm{AA}$ & 94 & $29(20-52)$ & $41.4 \pm 5.8$ & $27.6 \pm 7.7$ & & & \\
\hline $\mathrm{IDH}$ & & & & & $<0.0001$ & $3.30(1.91-5.70)$ & $<0.0001$ \\
\hline Mutant & 97 & $69(51-89)$ & $62.4 \pm 5.6$ & $53.0 \pm 6.9$ & & & \\
\hline Wild type & 45 & $15(11-18)$ & $22.8 \pm 6.4$ & $22.8 \pm 6.4$ & & & \\
\hline Histomolecular subgroup & & & & & $<0.0001$ & $2.35(1.67-3.31)$ & $<0.0001$ \\
\hline IDH-mutant 1p/19q-codeleted tumor & 42 & $76(32-89)$ & $3.4 \pm 8.3$ & $63.4 \pm 8.3$ & & & \\
\hline IDH-mutant 1p/19q-noncodeleted tumor & 54 & $52(34-57)$ & $59.9 \pm 8.0$ & $38.8 \pm 11.2$ & & & \\
\hline IDH wild-type tumor & 46 & $15(11-19)$ & $24.6 \pm 6.5$ & $24.6 \pm 6.5$ & & & \\
\hline MGMT & & & & & $<0.0001$ & $2.03(1.10-3.74)$ & 0.02 \\
\hline Methylated & 102 & $76(35-89)$ & $59.8 \pm 5.4$ & $50.6 \pm 6.7$ & & & \\
\hline Unmethylated & 40 & $12(11-20)$ & $24.3 \pm 7.5$ & $24.3 \pm 7.5$ & & & \\
\hline Adjuvant treatment & & & & & 0.0062 & $0.54(0.36-0.81)$ & 0.003 \\
\hline TMZ alone & 22 & $31(20-76)$ & $39 \pm 10.7$ & $39 \pm 10.7$ & & & \\
\hline RT+cTMZ \& aTMZ & 72 & $25(17-52)$ & $41.1 \pm 5.9$ & $31.5 \pm 6.7$ & & & \\
\hline $\mathrm{RT}+\mathrm{TMZ}$ & 48 & NR & $78.2 \pm 6.1$ & $78.2 \pm 6.1$ & & & \\
\hline
\end{tabular}

Boldface type indicates statistical significance.

tively (Table 5). The median OS time was NR, and the 1-, 3 -, and 5-year OS rates were 93.7\% $\pm 3.4 \%, 64.5 \% \pm 7.5 \%$, $64.5 \% \pm 7.5 \%$, respectively (Table 6).

For AA patients, the median PFS time was 29 months (95\% CI 20-52), and the 1-, 3-, and 5-year PFS rates were $73.4 \% \pm 4.5 \%, 41.4 \% \pm 5.8 \%$, and $27.6 \% \pm 7.7 \%$, respectively. The median OS time was 47 months (95\% CI 3794), and the 1-, 3-, and 5-year OS rates were $88.3 \% \pm 3.3 \%$, $62.5 \% \pm 5.7 \%$, and $47.6 \% \pm 6.9 \%$, respectively.
Concerning the three different histomolecular subgroups, for IDH-mutant 1p/19q-codeleted tumors, the median PFS time was 76 months (95\% CI 32-89), and the 1-, 3-, and 5-year PFS rates were 92.9\% $\pm 3.9 \%, 63.4 \%$ $\pm 8.3 \%$, and $63.4 \% \pm 8.3 \%$, respectively. For IDH-mutant 1p/19q-noncodeleted tumors, the median PFS time was 52 months (95\% CI 34-57), and the 1-, 3-, and 5-year PFS rates were $88.9 \% \pm 4.2 \%, 59.9 \% \pm 8.0 \%, 38.8 \% \pm 11.2 \%$, respectively. For IDH wild-type tumors, the median PFS 


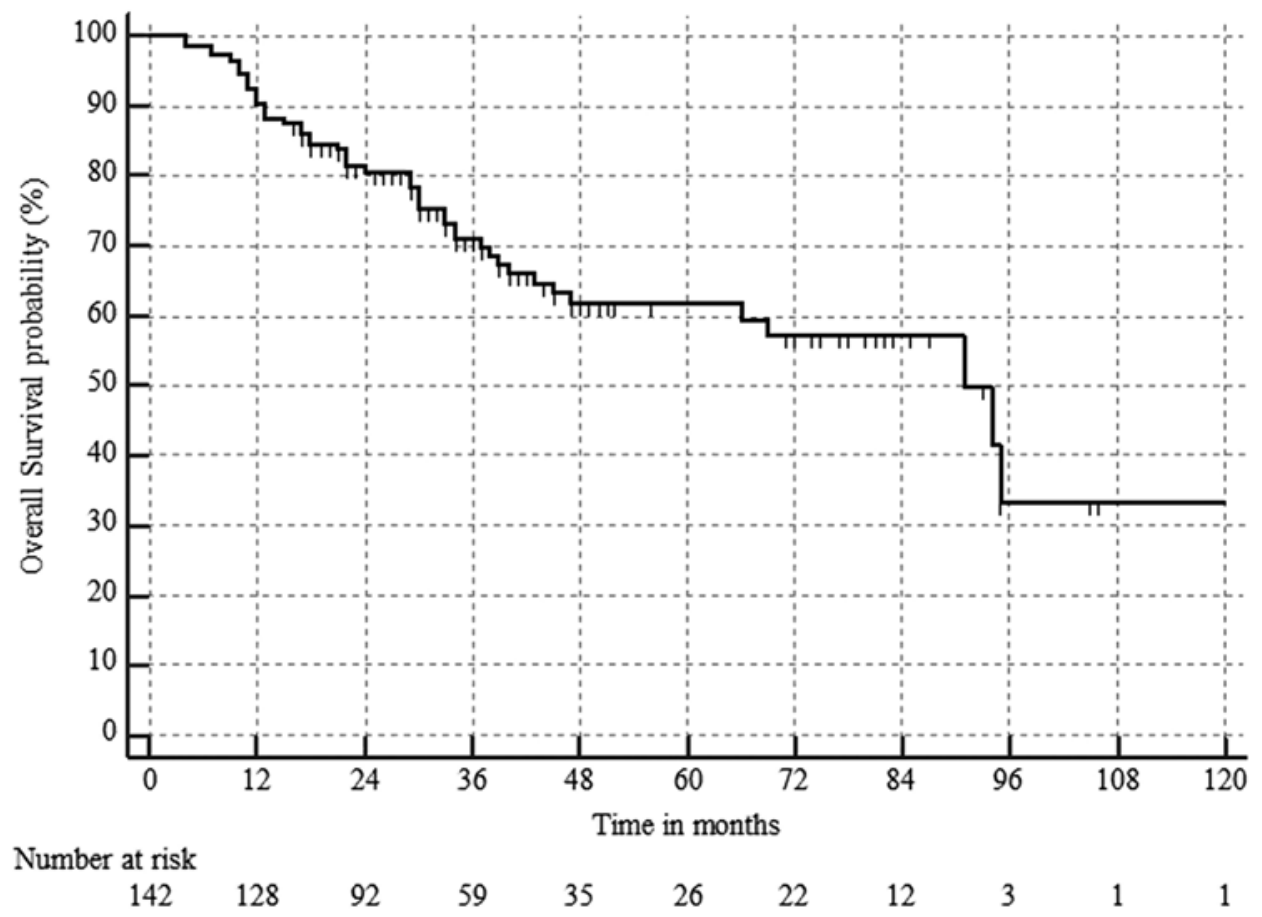

FIG. 2. OS of newly diagnosed AG patients.

time was 15 months (95\% CI 11-19), and the 1-, 3-, and 5 -year PFS rates were $54.3 \% \pm 7.3 \%, 24.6 \% \pm 6.5 \%$, and $24.6 \% \pm 6.5 \%$, respectively. For IDH-mutant $1 \mathrm{p} / 19 \mathrm{q}$-codeleted tumors, the median OS time was NR, and the 1-, 3-, and 5-year OS rates were 97.6\% $\pm 2.3 \%, 88.8 \% \pm 5.3 \%$, and $85.4 \% \pm 8.3 \%$, respectively. For IDH-mutant $1 \mathrm{p} / 19 \mathrm{q}-$ noncodeleted tumors, the median OS time was 94 months (95\% CI 66-95), and the 1-, 3-, and 5-year OS rates were $94.4 \% \pm 3.1 \%, 85.9 \% \pm 5.5 \%, 67.3 \% \pm 8.6 \%$, respectively. For IDH wild-type tumors, the median OS time was 30 months (95\% CI 18-40), and the 1-, 3-, and 5-year OS rates were $78.3 \% \pm 6.0 \%, 36.5 \% \pm 8.1 \%$, and $30.4 \% \pm 8.7 \%$, respectively. At the last observation time, 94 (66.2\%) patients were alive and 48 (33.8\%) dead.

\section{Toxicity}

Perioperative complications were recorded in $22(15.5 \%)$ patients. Cerebral hematoma, requiring additional reoperation, occurred in $2(1.4 \%)$ patients. A worsening of preoperative neurological deficits was found in 20 (14\%) cases, consisting of motor hemisyndrome, which recovered within 1 month, in 13 (9.2\%) cases; language deficit in 6 (4.2\%); and visual deficit in $1(0.7 \%)$. No perioperative mortality occurred. All patients were evaluated for toxicity during the time of adjuvant treatment. No severe hematological or neurological toxicity was recorded during concurrent radio-chemotherapy treatment, and neurological examination scores remained stable. Grade I and II radionecrosis was recorded in $4(2.8 \%)$ patients; no grade III-IV radionecrosis occurred. During adjuvant chemotherapy $4(2.8 \%)$ patients had grade III thrombocytopenia, $6(4.2 \%)$ patients had grade III neutropenia, and $2(1.4 \%)$ patients had grade
III anemia. No hematological grade IV toxicity occurred. Moderate to severe fatigue occurred in 24 (16.9\%) patients.

\section{Prognostic Factor Analysis}

Survival according to prognostic factors, including age, sex, KPS, EOR, RTV, histology (AO or AA), IDH and MGMT status, and histomolecular subgroups, was analyzed. The greatest benefit was observed in patients with oligodendroglial tumors, those who harbored the IDH mutation and those with MGMT methylation, those receiving the maximum safe resection without postoperative RTV, and those who underwent an adjuvant treatment consisting of sequential radiotherapy + TMZ. Details about prognostic factors influencing PFS and OS are shown in Tables 3 and 4. Considering that prior studies suggest that the impact of EOR on PFS may be more pronounced in the histomolecular IDH-mutant AA than IDH-mutant AO or IDH wild-type subgroups, PFS and OS for these three separate classes, and for AO and AA separately, were assessed. The impact of prognostic factors influencing PFS and OS for the entire cohort was evaluated as well. Results are shown in Tables 5 and 6.

\section{Treatment at Progression}

Among patients with disease progression, treatment was performed in $78(76.5 \%)$ cases and omitted in 24 $(23.5 \%)$ cases of rapid worsening of general and/or neurological condition. Treatment consisted of second-line chemotherapy alone for 44 patients, and of local treatment (surgery and/or radiotherapy) followed by chemotherapy in 34 patients, in accordance with the EOR and/or the previous treatments performed. 
TABLE 4. Kaplan-Meier OS according to subgroup analyses

\begin{tabular}{|c|c|c|c|c|c|c|c|}
\hline & \multirow{2}{*}{$\begin{array}{c}\text { No. of } \\
\text { Patients }\end{array}$} & \multirow{2}{*}{$\begin{array}{l}\text { Median OS, } \\
\text { Mos (range) }\end{array}$} & \multicolumn{2}{|c|}{ Mean \pm SD } & \multirow{2}{*}{$\begin{array}{l}\text { Univariate } \\
p \text { Value }\end{array}$} & \multirow{2}{*}{$\begin{array}{l}\text { Multivariate HR } \\
\quad(95 \% \mathrm{Cl})\end{array}$} & \multirow{2}{*}{$\begin{array}{c}\text { Multivariate } \\
\text { p Value }\end{array}$} \\
\hline & & & $3-Y r$ OS, \% & $5-Y r$ OS, \% & & & \\
\hline OS & 142 & 91 (66-95) & $70.9 \pm 4.2$ & $61.8 \pm 4.9$ & & & \\
\hline Sex & & & & & 0.64 & & \\
\hline Female & 54 & 94 (43-94) & $70.3 \pm 6.9$ & $59.5 \pm 8.2$ & & & \\
\hline Male & 84 & 91 (66-95) & $71.4 \pm 5.3$ & $63.3 \pm 6.0$ & & & \\
\hline Age, yrs & & & & & 0.055 & & \\
\hline$\leq 43$ & 76 & 94 (69-95) & $79.3 \pm 5.2$ & $70.1 \pm 6.3$ & & & \\
\hline$>43$ & 66 & NR & $61.8 \pm 6.5$ & $52.4 \pm 7.4$ & & & \\
\hline KPS score & & & & & 0.06 & & \\
\hline 90-100 & 120 & 94 (69-95) & $74.3 \pm 4.4$ & $66.5 \pm 5.1$ & & & \\
\hline 80 & 22 & $38(29-45)$ & $54.6 \pm 11.6$ & $39.0 \pm 12.5$ & & & \\
\hline EOR & & & & & 0.003 & $1.25(1.00-1.57)$ & 0.04 \\
\hline GTR & 80 & NR & $78.0 \pm 5.3$ & $67.9 \pm 6.6$ & & & \\
\hline NTR & 14 & NR & $73.3 \pm 13.2$ & $55.0 \pm 15$ & & & \\
\hline STR & 13 & 95 (69-NR) & $76.2 \pm 12.1$ & $76.2 \pm 12.1$ & & & \\
\hline $\mathrm{PR} / \mathrm{B}$ & 35 & $45(13-94)$ & $53.3 \pm 8.6$ & $46.7 \pm 9.7$ & & & \\
\hline RTV total & & & & & 0.004 & $2.05(1.02-4.13)$ & 0.04 \\
\hline No & 59 & NR & $83.5 \pm 5.8$ & $71.9 \pm 8$ & & & \\
\hline Yes & 83 & 69 (38-95) & $62.1 \pm 5.6$ & $54.7 \pm 6.1$ & & & \\
\hline CE RTV & & & & & 0.0001 & & \\
\hline No & 114 & 94 (69-95) & $76.6 \pm 4.6$ & $68.3 \pm 5.4$ & & & \\
\hline Yes & 28 & $21(13-45)$ & $46.4 \pm 9.4$ & $35.8 \pm 9.8$ & & & \\
\hline FLAIR RTV & & & & & 0.013 & & \\
\hline No & 62 & NR & $81.2 \pm 5.8$ & $70.4 \pm 7.7$ & & & \\
\hline Yes & 80 & 69 (38-95) & $66.6 \pm 5.5$ & $55.4 \pm 6.2$ & & & \\
\hline Histology & & & & & 0.0001 & $0.39(0.17-0.89)$ & 0.016 \\
\hline $\mathrm{AO}$ & 48 & NR & $86.2 \pm 5.3$ & $83.3 \pm 5.8$ & & & \\
\hline AA & 94 & 47 (37-94) & $62.5 \pm 5.7$ & $47.6 \pm 6.9$ & & & \\
\hline $\mathrm{IDH}$ & & & & & $<0.0001$ & $4.5(2.17-9.37)$ & 0.0001 \\
\hline Mutant & 97 & $95(91-95)$ & $87.3 \pm 3.8$ & $73.9 \pm 5.8$ & & & \\
\hline Wild type & 45 & $29(18-40)$ & $34.6 \pm 8.2$ & $27.7 \pm 9.0$ & & & \\
\hline Histomolecular subgroup & & & & & $<0.0001$ & $3.4(2.17-5.46)$ & $<0.0001$ \\
\hline IDH-mutant 1p/19q-codeleted tumor & 42 & NR & $88.8 \pm 5.3$ & $85.4 \pm 6.1$ & & & \\
\hline IDH-mutant 1p/19q-noncodeleted tumor & 54 & $94(66-95)$ & $85.9 \pm 5.5$ & $67.3 \pm 8.6$ & & & \\
\hline IDH wild-type tumor & 46 & $30(18-40)$ & $36.5 \pm 8.1$ & $30.4 \pm 8.7$ & & & \\
\hline MGMT & & & & & $<0.0001$ & $2.2(1.09-4.4)$ & 0.012 \\
\hline Methylated & 102 & $94(91-95)$ & $82.7 \pm 4.2$ & $72.9 \pm 5.3$ & & & \\
\hline Unmethylated & 40 & $22(15-47)$ & $40.6 \pm 8.5$ & $30.4 \pm 10.9$ & & & \\
\hline Adjuvant treatment & & & & & 0.11 & $2.2(1.09-4.4)$ & 0.012 \\
\hline TMZ alone & 22 & NR & $81.3 \pm 8.4$ & $71.8 \pm 9.7$ & & & \\
\hline RT+cTMZ \& aTMZ & 72 & 94 (39-95) & $64.0 \pm 5.9$ & $54.2 \pm 6.4$ & & & \\
\hline $\mathrm{RT}+\mathrm{TMZ}$ & 48 & NR & $80.7 \pm 6.6$ & $80.7 \pm 6.6$ & & & \\
\hline
\end{tabular}

Boldface type indicates statistical significance.

\section{Discussion}

The most recent data in the literature, resulting in the 2016 WHO CNS classification update, highlighted the role of tumor molecular profile as the most influential prognostic factor predicting outcome in newly diagnosed glioma patients. Most interestingly, IDH status was identified as the most predictive and prognostic molecular marker influencing survival, eventually resulting in the definition of distinct pathological entities with different behaviors, possibly requiring tailored therapeutic strategies. So far, three different cohesive tumor classes have been determined: IDH-mutant $1 \mathrm{p} / 19 \mathrm{q}$-codeleted tumors characterized by a good prognosis, IDH-mutant 1p/19q-noncodeleted tumors defined as an intermediate status, and IDH wild-type tumors that are likely to be immediate precursors of GBM with a similar median OS (1.7 years). ${ }^{11-16}$

To date, limited data are available about these new pathological subgroups, and optimal therapeutic approaches are yet to be clearly defined. In this changing landscape, incoming data and resulting suggestions from larger phase III 
TABLE 5. Kaplan-Meier PFS analysis according to different histomolecular subgroups and histology groups (AO and AA)

\begin{tabular}{|c|c|c|c|c|c|c|c|}
\hline & \multirow{2}{*}{$\begin{array}{c}\text { No. of } \\
\text { Patients } \\
(\%)\end{array}$} & \multirow{2}{*}{$\begin{array}{c}\text { Median PFS, } \\
\text { Mos (range) }\end{array}$} & \multicolumn{2}{|c|}{ Mean \pm SD } & \multirow{2}{*}{$\begin{array}{l}\text { Univariate } \\
\text { p Value }\end{array}$} & \multirow{2}{*}{$\begin{array}{l}\text { Multivariate } \\
\text { p Value }\end{array}$} & \multirow{2}{*}{$\begin{array}{c}\text { Multivariate HR } \\
(95 \% \mathrm{Cl})\end{array}$} \\
\hline & & & 3-Yr PFS, \% & $5-Y r$ PFS, \% & & & \\
\hline \multicolumn{8}{|l|}{$\begin{array}{l}\text { IDH-mutant } 1 \mathrm{p} / 19 \mathrm{q}- \\
\text { codeleted tumor }\end{array}$} \\
\hline PFS & 42 & $76(32-89)$ & $63.4 \pm 8.3$ & $63.4 \pm 8.3$ & & & \\
\hline EOR & & & & & 0.15 & & \\
\hline GTR & $31(73.8)$ & $76(76-76)$ & $71.7 \pm 9.4$ & $71.7 \pm 9.4$ & & & \\
\hline NTR & $6(14.3)$ & $25(18-25)$ & $50 \pm 20.4$ & $50 \pm 20.4$ & & & \\
\hline STR & $3(7.1)$ & $24(21-69)$ & $33.3 \pm 27.2$ & $33.3 \pm 27.2$ & & & \\
\hline $\mathrm{PR} / \mathrm{B}$ & $2(4.8)$ & $32(32-89)$ & $50 \pm 35.4$ & $50 \pm 35.4$ & & & \\
\hline \multicolumn{8}{|l|}{$\begin{array}{l}\text { IDH-mutant 1p/19q- } \\
\text { noncodeleted tumor }\end{array}$} \\
\hline PFS & 54 & $52(34-57)$ & $59.9 \pm 8.0$ & $38.8 \pm 11.2$ & & & \\
\hline EOR & & & & & 0.38 & & \\
\hline GTR & $25(46.3)$ & NR & $64.5 \pm 11.5$ & $64.5 \pm 11.5$ & & & \\
\hline NTR & $6(11.1)$ & $35(33-35)$ & $50 \pm 25$ & $50 \pm 25$ & & & \\
\hline STR & $8(14.8)$ & $57(34-57)$ & $64.3 \pm 21$ & $32.1 \pm 25$ & & & \\
\hline $\mathrm{PR} / \mathrm{B}$ & $15(27.8)$ & $51(20-52)$ & $56 \pm 13.7$ & 0 & & & \\
\hline \multicolumn{8}{|l|}{ IDH wild-type tumor } \\
\hline PFS & 46 & $15(11-19)$ & $24.6 \pm 6.5$ & $24.6 \pm 6.5$ & & & \\
\hline EOR & & & & & 0.0004 & & \\
\hline GTR & $24(52.3)$ & $22(17-78)$ & $38.7 \pm 10.5$ & $38.7 \pm 10.5$ & & & \\
\hline NTR & $2(4.3)$ & $13(13-18)$ & 0 & 0 & & & \\
\hline STR & $2(4.3)$ & $4(4-9)$ & 0 & 0 & & & \\
\hline $\mathrm{PR} / \mathrm{B}$ & $18(39.1)$ & $10(7-12)$ & $11.1 \pm 7.4$ & $11.1 \pm 7.4$ & & & \\
\hline \multicolumn{8}{|l|}{$\mathrm{AO}$} \\
\hline PFS & 48 & 78 (32-89) & $64.5 \pm 7.5$ & $64.5 \pm 7.5$ & & & \\
\hline EOR & & & & & 0.16 & & \\
\hline GTR & $35(72.9)$ & $78(76-78)$ & $72.9 \pm 8.5$ & $72.9 \pm 8.5$ & & & \\
\hline NTR & $6(12.5)$ & $25(18-25)$ & $50 \pm 20.4$ & $50 \pm 20.4$ & & & \\
\hline STR & $3(6.2)$ & $24(21-69)$ & $33.3 \pm 27.2$ & $33.3 \pm 27.2$ & & & \\
\hline PR/B & $4(8.3)$ & $32(5-89)$ & $50 \pm 25$ & $50 \pm 25$ & & & \\
\hline IDH & & & & & 0.56 & & \\
\hline Mutant & $44(91.7)$ & $76(32-89)$ & $63 \pm 8.0$ & $63 \pm 8.0$ & & & \\
\hline Wild type & $4(8.3)$ & NR & $75 \pm 21.5$ & $75 \pm 21.5$ & & & \\
\hline MGMT & & & & & 0.0006 & & \\
\hline Methylated & $41(85.4)$ & $78(76-89)$ & $66.3 \pm 8.0$ & $66.3 \pm 8.0$ & & & \\
\hline Unmethylated & $7(14.6)$ & $8(5-69)$ & $40 \pm 21.9$ & $40 \pm 21.9$ & & & \\
\hline Adjuvant treatment & & & & & 0.62 & & \\
\hline TMZ alone & 13 & $76(27-89)$ & $59.2 \pm 14.1$ & $59.2 \pm 14.1$ & & & \\
\hline $\mathrm{RT}+\mathrm{cTMZ} \&$ aTMZ & 21 & NR & $61.5 \pm 10.7$ & $61.5 \pm 10.7$ & & & \\
\hline $\mathrm{RT}+\mathrm{TMZ}$ & 14 & NR & $85.7 \pm 9.3$ & $85.7 \pm 9.3$ & & & \\
\hline \multicolumn{8}{|l|}{$\mathrm{AA}$} \\
\hline PFS & 94 & $29(20-52)$ & $41.4 \pm 5.8$ & $27.6 \pm 7.7$ & & & \\
\hline EOR & & & & & 0.01 & 0.003 & $1.44(1.13-1.85)$ \\
\hline GTR & $45(47.9)$ & $33(22-33)$ & $48.4 \pm 8.6$ & $48.4 \pm 8.6$ & & & \\
\hline NTR & $8(8.5)$ & $35(18-35)$ & $37.5 \pm 20.3$ & $37.5 \pm 20.3$ & & & \\
\hline STR & $10(10.6)$ & $57(17-57)$ & $51.4 \pm 20.7$ & $25.7 \pm 20.4$ & & & \\
\hline $\mathrm{PR} / \mathrm{B}$ & $31(33.0)$ & $12(11-25)$ & $30.5 \pm 8.5$ & 0 & & & \\
\hline IDH & & & & & $<0.0001$ & $<0.0001$ & $5.37(2.62-11.01)$ \\
\hline Mutant & $53(56.4)$ & $52(34-57)$ & $61 \pm 8.1$ & $39.5 \pm 11.4$ & & & \\
\hline Wild type & $41(43.6)$ & $13(11-18)$ & $17.1 \pm 6.2$ & $17.1 \pm 6.2$ & & & \\
\hline
\end{tabular}


TABLE 5. Kaplan-Meier PFS analysis according to different histomolecular subgroups and histology groups (AO and $\mathrm{AA}$ )

\begin{tabular}{|c|c|c|c|c|c|c|c|}
\hline & \multirow{2}{*}{$\begin{array}{c}\text { No. of } \\
\text { Patients } \\
(\%)\end{array}$} & \multirow{2}{*}{$\begin{array}{c}\text { Median PFS, } \\
\text { Mos (range) }\end{array}$} & \multicolumn{2}{|c|}{ Mean \pm SD } & \multirow{2}{*}{$\begin{array}{l}\text { Univariate } \\
\text { p Value }\end{array}$} & \multirow{2}{*}{$\begin{array}{c}\text { Multivariate } \\
\text { p Value }\end{array}$} & \multirow{2}{*}{$\begin{array}{c}\text { Multivariate HR } \\
(95 \% \mathrm{Cl})\end{array}$} \\
\hline & & & $3-Y r$ PFS, \% & 5 -Yr PFS, \% & & & \\
\hline MGMT & & & & & $<0.0001$ & 0.84 & $1.05(0.63-1.74)$ \\
\hline Methylated & $61(64.9)$ & $51(33-57)$ & $54.6 \pm 7.5$ & $34 \pm 10.8$ & & & \\
\hline Unmethylated & $33(35.1)$ & $12(10-18)$ & $10.3 \pm 6.3$ & $10.3 \pm 6.3$ & & & \\
\hline Adjuvant treatment & & & & & 0.002 & 0.01 & $0.51(0.30-0.85)$ \\
\hline TMZ alone & 9 & $20(16-33)$ & $11.1 \pm 10.5$ & $11.1 \pm 10.5$ & & & \\
\hline RT+cTMZ \& aTMZ & 51 & $20(13-33)$ & $32.3 \pm 6.8$ & $19.4 \pm 7.1$ & & & \\
\hline $\mathrm{RT}+\mathrm{TMZ}$ & 34 & NR & $75.3 \pm 7.6$ & $75.3 \pm 7.6$ & & & \\
\hline
\end{tabular}

Boldface type indicates statistical significance.

randomized trials suffer several limitations due to the confounding effect related to the inclusion of mixed anaplastic oligoastrocytoma (AOA; removed in the 2016 update of the WHO classification), and the uncertain value of tumor molecular assessment. The NOA-04 phase III trial compared the efficacy and safety of radiotherapy, followed by chemotherapy at progression with the reverse sequence in patients with newly diagnosed AGs. The authors concluded that initial radiotherapy or chemotherapy achieved comparable results, but a long-term analysis did not confirm the previous data. To underscore, the finding of IDH1 mutations is a novel positive prognostic factor that is stronger than $1 \mathrm{p} / 19 \mathrm{q}$ codeletion or MGMT promoter methylation., ${ }^{910}$

In the RTOG 9402 trial, patients with AO and AOA were randomly assigned to PCV chemotherapy followed by radiotherapy versus postoperative radiotherapy alone. The primary endpoint was OS. A longer PFS was recorded after PCV plus radiotherapy but with significantly increased toxicity and without benefit on survival. ${ }^{7}$ In the same population (AO/AOA), the EORTC 26951 trial evaluated the benefit, adding 6 cycles of PCV chemotherapy to radiotherapy, to PFS and OS. Gains in OS and PFS were observed with adjuvant PCV chemotherapy, above all in 1p/19q-codeleted tumors. ${ }^{8}$ More recently, the interim results of the CATNON trial, assessing the role of TMZ in newly diagnosed 1p/19q-noncodeleted AGs, showed a significant survival benefit in patients undergoing adjuvant TMZ.18

Table 7 summarizes the results of these trials in terms of PFS, OS, and prognostic factors detected as predicting survival. Considering this evolving scenario, we aimed at evaluating the outcome of newly diagnosed AG patients treated at our institution, with the main objective of identifying prognostic factors impacting survival that are associated with IDH status. In addition, considering the different treatment approaches applied in this cohort, we sought to assess which therapeutic strategy may prove most effective. Newly diagnosed AG patients with complete clinical, radiological, histopathological, and molecular data were included in this evaluation. Several prognostic factors related to patient, tumor, and treatment characteristics were investigated. As expected, the IDH status was the most important prognostic factor influencing outcome, more than histopathological features $(\mathrm{p}=0.0001$; HR 4.5 [95\% CI 2.17-9.37]), with a median OS time and a 5-year OS rate for IDH-mutant tumors of 95 months and $74 \%$, versus 29 months and $28 \%$ for IDH wild-type tumors, respectively. Of note, a large part (87\%) of IDH wild-type AGs in our cohort were noncodeleted gliomas, confirming the dismal prognosis of the so-called "tumor class III." Likewise, IDH status strongly impacted PFS, with a median PFS time of 15 months and a 4-year PFS rate of $20 \%$ in cases of IDH wild-type disease. This result probably implies that, in these patients, a more aggressive treatment is required; however, to date, available data from the literature do not allow clarification of the optimal therapeutic strategy. Secondarily, MGMT status was significantly correlated with both PFS ( $p=0.02$; HR 2.03 [95\% CI 1.10-3.74]) and OS $(\mathrm{p}=0.01$; HR 2.2 [95\% CI 1.09-4.4]). Previous reports showed superior PFS for patients with methylated MGMT, although the impact on OS was mild. ${ }^{3}$ This finding, somewhat surprisingly, could be explained by the high prevalence of this condition in a large part of our study population, and the consistent use of TMZ in all of them.

While the influence of the tumor molecular profile on the prognosis for AG patients and the tumor response to chemotherapy have been widely described and their value well established, this was not confirmed for other prognostic factors, such as EOR. Although in patients with GBM retrospective analysis of prospective data extrapolated from randomized trials has yielded level $2 b$ evidence that the EOR is positively associated with OS,,$^{21-25}$ limited evidence is available on the relationship between the EOR and the level of clinical benefit for patients with AGs. ${ }^{26-28}$ In our previous experience, conducted on a more heterogeneous population that included patients affected by high-grade gliomas and for whom the value of a tumor molecular profile was not established, the EOR and the RTV proved to significantly influence PFS. ${ }^{29}$ These data have been confirmed in the present study on both PFS and OS. Most notably, the 5-year PFS rate was $60 \%$ for patients undergoing GTR compared with $46 \%, 31 \%$, and $11 \%$ for those who received NTR, STR, and PR, respectively. It is also noteworthy that OS was improved when GTR was performed ( $\mathrm{p}=0.04$; HR 1.25 [95\% CI 1.00-1.57]) on both univariate and multivariate analyses. 
TABLE 6. Kaplan-Meier OS analyses according to different histomolecular subgroups and histology groups (AO and $\mathrm{AA}$ )

\begin{tabular}{|c|c|c|c|c|c|c|c|}
\hline & \multirow{2}{*}{$\begin{array}{c}\text { No. of } \\
\text { Patients (\%) }\end{array}$} & \multirow{2}{*}{$\begin{array}{l}\text { Median OS, } \\
\text { Mos (range) }\end{array}$} & \multicolumn{2}{|c|}{ Mean \pm SD } & \multirow{2}{*}{$\begin{array}{l}\text { Univariate } \\
\text { p Value }\end{array}$} & \multirow{2}{*}{$\begin{array}{l}\text { Multivariate } \\
\text { p Value }\end{array}$} & \multirow{2}{*}{$\begin{array}{l}\text { Multivariate HR } \\
(95 \% \mathrm{Cl})\end{array}$} \\
\hline & & & $3-Y r$ OS, $\%$ & $5-Y r$ OS, $\%$ & & & \\
\hline \multicolumn{8}{|l|}{$\begin{array}{l}\text { IDH-mutant 1p/19q- } \\
\text { codeleted tumor }\end{array}$} \\
\hline OS & 42 & NR & $88.8 \pm 5.3$ & $85.4 \pm 8.3$ & & & \\
\hline EOR & & & & & 0.46 & & \\
\hline GTR & $31(73.8)$ & $N R$ & $92.9 \pm 4.8$ & $92.9 \pm 4.8$ & & & \\
\hline NTR & $6(14.3)$ & NR & $83.3 \pm 15.2$ & $66.7 \pm 19.2$ & & & \\
\hline STR & $3(7.1)$ & NR & $66.7 \pm 27.2$ & $66.7 \pm 27.2$ & & & \\
\hline $\mathrm{PR} / \mathrm{B}$ & $2(4.8)$ & NR & 100 & 100 & & & \\
\hline \multicolumn{8}{|l|}{$\begin{array}{l}\text { IDH-mutant } 1 \mathrm{p} / 19 \mathrm{q}- \\
\text { noncodeleted tumor }\end{array}$} \\
\hline OS & 54 & $94(66-95)$ & $85.9 \pm 5.5$ & $67.3 \pm 8.6$ & & & \\
\hline EOR & & & & & 0.58 & & \\
\hline GTR & $25(46.3)$ & NR & $84.7 \pm 8.2$ & $57.8 \pm 14.2$ & & & \\
\hline NTR & $6(11.1)$ & $38(34-38)$ & $75 \pm 21.7$ & $50 \pm 25$ & & & \\
\hline STR & $8(14.8)$ & 95 (69-NR) & 100 & 100 & & & \\
\hline $\mathrm{PR} / \mathrm{B}$ & $15(27.8)$ & $66(45-94)$ & 100 & $72.2 \pm 15.1$ & & & \\
\hline \multicolumn{8}{|l|}{ IDH wild-type tumor } \\
\hline OS & 46 & $30(18-40)$ & $36.5 \pm 8.1$ & $30.4 \pm 8.7$ & & & \\
\hline EOR & & & & & 0.0008 & & \\
\hline GTR & $24(52.3)$ & $40(30-40)$ & $53.8 \pm 11.9$ & $43.1 \pm 13.5$ & & & \\
\hline NTR & $2(4.3)$ & 30 & 0 & 0 & & & \\
\hline STR & $2(4.3)$ & $11(11-15)$ & 0 & 0 & & & \\
\hline $\mathrm{PR} / \mathrm{B}$ & $18(39.1)$ & $13(11-21)$ & $20 \pm 9.8$ & $20 \pm 9.8$ & & & \\
\hline \multicolumn{8}{|l|}{$\mathrm{AO}$} \\
\hline OS & 48 & $78(32-89)$ & $64.5 \pm 7.5$ & $64.5 \pm 7.5$ & & & \\
\hline EOR & & & & & 0.64 & & \\
\hline GTR & 35 (72.9) & NR & $90.9 \pm 5.0$ & $90.9 \pm 5.0$ & & & \\
\hline NTR & $6(12.5)$ & NR & $83.3 \pm 15.2$ & $66.7 \pm 19.2$ & & & \\
\hline STR & $3(6.2)$ & NR & $66.7 \pm 27.2$ & $66.7 \pm 27.2$ & & & \\
\hline $\mathrm{PR} / \mathrm{B}$ & $4(8.3)$ & NR & $75 \pm 21.7$ & $75 \pm 21.7$ & & & \\
\hline IDH & & & & & 0.53 & & \\
\hline Mutant & $44(91.7)$ & NR & $87.1 \pm 5.4$ & $83.8 \pm 6.1$ & & & \\
\hline Wild type & $4(8.3)$ & NR & $75 \pm 21.7$ & $75 \pm 21.7$ & & & \\
\hline MGMT & & & & & 0.0002 & & \\
\hline Methylated & $41(85.4)$ & NR & $91.6 \pm 4.7$ & $88.3 \pm 5.5$ & & & \\
\hline Unmethylated & $7(14.6)$ & $22(7-22)$ & $30 \pm 23.9$ & $30 \pm 23.9$ & & & \\
\hline Adjuvant treatment & & & & & 0.27 & & \\
\hline $\mathrm{CHT}$ alone & 13 & NR & 100 & 100 & & & \\
\hline $\mathrm{RT}+\mathrm{cCHT} \& \mathrm{aCHT}$ & 21 & NR & $80.7 \pm 8.6$ & $80.7 \pm 8.6$ & & & \\
\hline $\mathrm{RT}+\mathrm{CHT}$ & 14 & NR & $85.7 \pm 9.3$ & $85.7 \pm 9.3$ & & & \\
\hline \multicolumn{8}{|l|}{$\mathrm{AA}$} \\
\hline OS & 94 & $29(20-52)$ & $41.4 \pm 5.8$ & $27.6 \pm 7.7$ & & & \\
\hline EOR & & & & & 0.04 & 0.02 & $1.38(1.05-1.82)$ \\
\hline GTR & $45(47.9)$ & $47(37-47)$ & $67.7 \pm 8.3$ & $44.2 \pm 11.0$ & & & \\
\hline NTR & $8(8.5)$ & $38(34-38)$ & $62.5 \pm 21.3$ & $41.7 \pm 22.2$ & & & \\
\hline STR & $10(10.6)$ & 95 (69-NR) & $80 \pm 12.6$ & $80 \pm 12.6$ & & & \\
\hline $\mathrm{PR} / \mathrm{B}$ & $31(33.0)$ & $45(13-94)$ & $50.3 \pm 9.2$ & $41.9 \pm 10.8$ & & & \\
\hline $\mathrm{IDH}$ & & & & & $<0.0001$ & $<0.0001$ & $8.42(8.30-21.4)$ \\
\hline Mutant & $53(56.4)$ & $94(66-95)$ & $87.6 \pm 5.3$ & $68.6 \pm 8.6$ & & & \\
\hline Wild type & 41 (43.6) & $24(17-33)$ & $28.7 \pm 8.6$ & $14.3 \pm 11.0$ & & & \\
\hline
\end{tabular}


TABLE 6. Kaplan-Meier OS analyses according to different histomolecular subgroups and histology groups (AO and AA)

\begin{tabular}{|c|c|c|c|c|c|c|c|}
\hline & \multirow{2}{*}{$\begin{array}{c}\text { No. of } \\
\text { Patients (\%) }\end{array}$} & \multirow{2}{*}{$\begin{array}{l}\text { Median OS, } \\
\text { Mos (range) }\end{array}$} & \multicolumn{2}{|c|}{ Mean \pm SD } & \multirow{2}{*}{$\begin{array}{l}\text { Univariate } \\
\text { p Value }\end{array}$} & \multirow{2}{*}{$\begin{array}{c}\text { Multivariate } \\
\text { p Value }\end{array}$} & \multirow{2}{*}{$\begin{array}{c}\text { Multivariate HR } \\
\quad(95 \% \mathrm{Cl})\end{array}$} \\
\hline & & & $3-Y r$ OS, $\%$ & $5-Y r$ OS, $\%$ & & & \\
\hline MGMT & & & & & $<0.0001$ & 0.37 & $1.30(0.72-1.35)$ \\
\hline Methylated & $61(64.9)$ & $69(43-95)$ & $75.9 \pm 6.5$ & $59 \pm 8.4$ & & & \\
\hline Unmethylated & $33(35.1)$ & $18(13-30)$ & $30.7 \pm 9.7$ & $20.5 \pm 10.6$ & & & \\
\hline Adjuvant treatment & & & & & 0.13 & 0.17 & $0.63(0.33-1.21)$ \\
\hline TMZ alone & 9 & $38(33-66)$ & $55.6 \pm 16.6$ & $33.3 \pm 15.7$ & & & \\
\hline RT+cTMZ \& aTMZ & 51 & $45(30-94)$ & $56.5 \pm 7.5$ & $43.4 \pm 8.1$ & & & \\
\hline $\mathrm{RT}+\mathrm{TMZ}$ & 34 & $\mathrm{NR}$ & $79.6 \pm 7.8$ & $79.6 \pm 7.8$ & & & \\
\hline
\end{tabular}

Boldface type indicates statistical significance.

In our cohort, the EOR was determined on both postcontrast T1-weighted MRI and FLAIR sequences. Considering that a large number of these tumors are characterized by prevalent FLAIR abnormalities, resection of this area, if functionally feasible, is recommended. Although GTR significantly influences both PFS and OS, it is not always feasible. In this context, surgery should be focused on minimizing RTV. Concerning this issue, one of the most important published papers is that of Beiko et al., ${ }^{29}$ evaluating the impact of resection on survival in a large series of malignant astrocytomas. The authors recorded a survival benefit from maximal resection, for both enhancing and nonenhancing tumors, in IDH1-mutant subgroups. Although our results underlined the therapeutic benefit from maximal resection, no significant differences were recorded for IDH-mutant $1 \mathrm{p} / 19 \mathrm{q}$-codeleted or $1 \mathrm{p} / 19 \mathrm{q}-$ noncodeleted patients who underwent GTR with respect to NTR, STR, PR, or biopsy. The different results obtained are probably related to several factors, including the different tumor histology evaluated, the inclusion of $\mathrm{AO}$ patients and exclusion of GBM patients, the relatively small series analyzed for different histomolecular subgroups, and the large number of our patients receiving a maximal resection, which made the assessment by groups less reliable.

The role of RTV is more difficult to ascertain. Considering that most AGs display FLAIR alterations with or without CE uptake abnormalities on MRI, both components have to be considered when an RTV evaluation is performed. In our series, only a minority of patients had CE RTV, and they were characterized by a more unfavorable phenotype (mostly AA, IDH wild-type, and unmethylated MGMT). Hence, the presence of CE RTV yielded a greater impact on PFS and OS than did FLAIR RTV.

Finally, we wanted to evaluate patient outcome with respect to the treatment approaches that were undertaken. Following resection to a variable extent, patients received

TABLE 7. Randomized trials concerning AAs

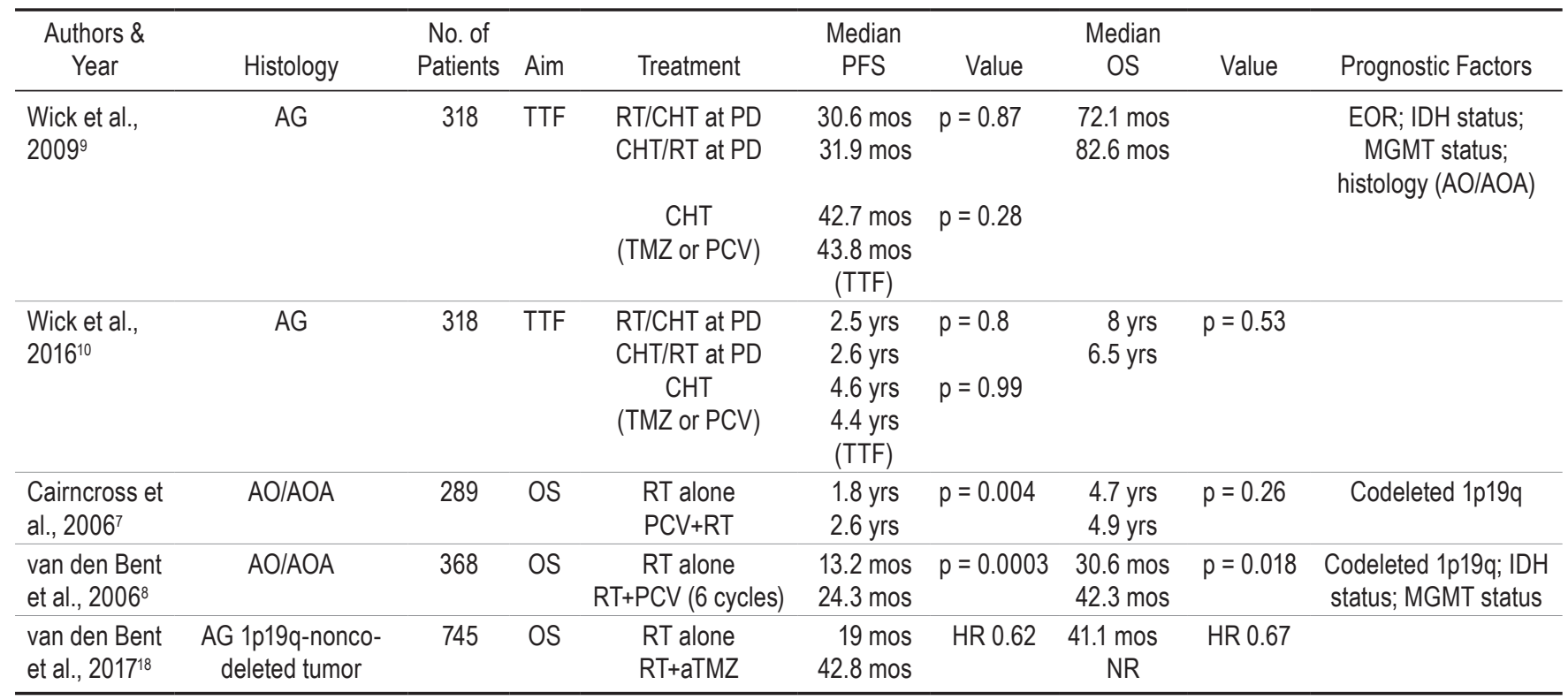

$\mathrm{CHT}=$ chemotherapy; $\mathrm{PD}=$ disease progression; TTF = time to treatment failure. 
adjuvant chemotherapy alone, radiotherapy with concomitant and adjuvant TMZ, or radiotherapy + TMZ. We decided to administer TMZ in place of PCV chemotherapy because of the comparable results reported in the literature and the greater tolerability of the drug. The obtained results were highly satisfactory and compared favorably with results from the literature, with a median PFS interval and 5-year PFS rate of 35 months and 43\%, respectively, and a median OS time and 5-year OS rate of 91 months and $62 \%$, respectively. A greater benefit has been observed in patients receiving a sequential radiotherapy-chemotherapy schedule compared with chemotherapy alone, or radiotherapy with concomitant and adjuvant chemotherapy: about $80 \%$ of patients showed durable disease control and were alive at 5 years. Unfortunately, the survival benefit of the use of concomitant TMZ has not yet been clarified and remains an open question.

The second interim and the first molecular analyses of the CATNON trial presented at ASCO 2019 regarding 1p/19q-noncodeleted AA suggested that there was no benefit of concurrent chemotherapy on survival in the entire population, no benefit of concurrent and adjuvant chemotherapy in IDH wild-type AA, and a nonsignificant trend in favor of concomitant and adjuvant TMZ for IDH-mutant AA. A limited number of younger patients with a more favorable tumor biological profile and receiving maximal resection underwent adjuvant chemotherapy alone and radiotherapy at progression. Progression or relapse within 2 years from the primary diagnosis occurred in more than half of the patients, confirming the benefit of adjuvant radiotherapy, albeit in the presence of a favorable histopathological and molecular profile. Our results confirmed previous reports that questioned the role of concurrent TMZ.

We acknowledge that our analysis suffers from several limitations related to the retrospective nature of the study, the inclusion of both $\mathrm{AO}$ and $\mathrm{AA}$, the different adjuvant treatments employed, the limited sample size, and the short follow-up time. To our knowledge, this is one of a few studies that has assessed prognostic factors predicting the prognosis for newly diagnosed AG patients in detail in light of the WHO 2016 CNS classification, with the main aim of providing a contribution to clinical decision-making in this extremely heterogeneous set of primary brain tumors.

\section{Conclusions}

The results of our analysis suggest that other prognostic factors, such as EOR and radiotherapy, have to be considered in addition to IDH status and underscore the fundamental role of adjuvant radiotherapy in all AG patients. Patients who had better outcomes were those with IDHmutant tumors and those with methylated MGMT, those who received maximal safe resection without RTV, and those in whom adjuvant radiotherapy had been performed. There are no definitive answers concerning the optimal chemotherapy treatment to deliver and the schedule to use.

\section{References}

1. Brat DJ, Verhaak RGW, Aldape KD, et al. Comprehensive, integrative genomic analysis of diffuse lower-grade gliomas. N Engl J Med. 2015;372(26):2481-2498.
2. Brell M, Tortosa A, Verger E, et al. Prognostic significance of $O^{6}$-methylguanine-DNA methyltransferase determined by promoter hypermethylation and immunohistochemical expression in anaplastic gliomas. Clin Cancer Res. 2005;11(14): 5167-5174.

3. Stupp R, Mason WP, van den Bent MJ, et al. Radiotherapy plus concomitant and adjuvant temozolomide for glioblastoma. N Engl J Med. 2005;352(10):987-996.

4. Chahlavi A, Kanner A, Peereboom D, et al. Impact of chromosome 1p status in response of oligodendroglioma to temozolomide: preliminary results. J Neurooncol. 2003;61(3): 267-273.

5. Thiessen B, Maguire JA, McNeil K, et al. Loss of heterozygosity for loci on chromosome arms $1 \mathrm{p}$ and $10 \mathrm{q}$ in oligodendroglial tumors: relationship to outcome and chemosensitivity. J Neurooncol. 2003;64(3):271-278.

6. Levin VA, Silver P, Hannigan J, et al. Superiority of postradiotherapy adjuvant chemotherapy with CCNU, procarbazine, and vincristine (PCV) over BCNU for anaplastic gliomas: NCOG 6G61 final report. Int J Radiat Oncol Biol Phys. 1990;18(2):321-324.

7. Cairncross G, Berkey B, Shaw E, et al. Phase III trial of chemotherapy plus radiotherapy compared with radiotherapy alone for pure and mixed anaplastic oligodendroglioma: Intergroup Radiation Therapy Oncology Group Trial 9402. J Clin Oncol. 2006;24(18):2707-2714.

8. van den Bent MJ, Carpentier AF, Brandes AA, et al. Adjuvant procarbazine, lomustine, and vincristine improves progression-free survival but not overall survival in newly diagnosed anaplastic oligodendrogliomas and oligoastrocytomas: a randomized European Organisation for Research and Treatment of Cancer phase III trial. J Clin Oncol. 2006; 24(18):2715-2722.

9. Wick W, Hartmann C, Engel C, et al. NOA-04 randomized phase III trial of sequential radiochemotherapy of anaplastic glioma with procarbazine, lomustine, and vincristine or temozolomide. J Clin Oncol. 2009;27(35):5874-5880.

10. Wick W, Roth P, Hartmann C, et al. Long-term analysis of the NOA-04 randomized phase III trial of sequential radiochemotherapy of anaplastic glioma with PCV or temozolomide. Neuro Oncol. 2016;18(11):1529-1537.

11. Frenel JS, Leux C, Loussouarn D, et al. Combining two biomarkers, IDH1/2 mutations and 1p/19q codeletion, to stratify anaplastic oligodendroglioma in three groups: a single-center experience. J Neurooncol. 2013;114(1):85-91.

12. Olar A, Wani KM, Alfaro-Munoz KD, et al. IDH mutation status and role of WHO grade and mitotic index in overall survival in grade II-III diffuse gliomas. Acta Neuropathol. 2015;129(4):585-596.

13. Jiang H, Ren X, Cui X, et al. $1 \mathrm{p} / 19 \mathrm{q}$ codeletion and IDH1/2 mutation identified a subtype of anaplastic oligoastrocytomas with prognosis as favorable as anaplastic oligodendrogliomas. Neuro Oncol. 2013;15(6):775-782.

14. Louis DN, Perry A, Burger P, et al. International Society of Neuropathology-Haarlem consensus guidelines for nervous system tumor classification and grading. Brain Pathol. 2014; 24(5):429-435.

15. Wiestler B, Capper D, Sill M, et al. Integrated DNA methylation and copy-number profiling identify three clinically and biologically relevant groups of anaplastic glioma. Acta Neuropathol. 2014;128(4):561-571.

16. Suzuki H, Aoki K, Chiba K, et al. Mutational landscape and clonal architecture in grade II and III gliomas. Nat Genet. 2015;47(5):458-468.

17. Louis DN, Perry A, Reifenberger G, et al. The 2016 World Health Organization Classification of Tumors of the Central Nervous System: a summary. Acta Neuropathol. 2016;131(6): 803-820.

18. van den Bent MJ, Baumert B, Erridge SC, et al. Interim re- 
sults from the CATNON trial (EORTC study 26053-22054) of treatment with concurrent and adjuvant temozolomide for $1 \mathrm{p} / 19 \mathrm{q}$ non-co-deleted anaplastic glioma: a phase 3 , randomised, open-label intergroup study. Lancet. 2017; 390(10103):1645-1653.

19. Sanai N, Berger MS. Glioma extent of resection and its impact on patient outcome. Neurosurgery. 2008;62(4):753-766.

20. Wen PY, Macdonald DR, Reardon DA, et al. Updated response assessment criteria for high-grade gliomas: Response Assessment in Neuro-Oncology working group. J Clin Oncol. 2010;28(11):1963-1972.

21. Chaichana KL, Jusue-Torres I, Navarro-Ramirez R, et al. Establishing percent resection and residual volume thresholds affecting survival and recurrence for patients with newly diagnosed intracranial glioblastoma. Neuro Oncol. 2014;16(1): $113-122$.

22. Grabowski MM, Recinos PF, Nowacki AS, et al. Residual tumor volume versus extent of resection: predictors of survival after surgery for glioblastoma. J Neurosurg. 2014;121(5): $1115-1123$

23. Stummer W, Reulen HJ, Meinel T, et al. Extent of resection and survival in glioblastoma multiforme: identification of and adjustment for bias. Neurosurgery. 2008;62(3):564-576.

24. Sanai N, Polley MY, McDermott MW, et al. An extent of resection threshold for newly diagnosed glioblastomas. J Neurosurg. 2011;115(1):3-8.

25. Li YM, Suki D, Hess K, Sawaya R. The influence of maximum safe resection of glioblastoma on survival in 1229 patients: Can we do better than gross-total resection? J Neurosurg. 2016;124(4):977-988.

26. Yamaguchi S, Kobayashi H, Terasaka S, et al. The impact of extent of resection and histological subtype on the outcome of adult patients with high-grade gliomas. Jpn J Clin Oncol. 2012;42(4):270-277.

27. McGirt MJ, Chaichana KL, Gathinji M, et al. Independent association of extent of resection with survival in patients with malignant brain astrocytoma. J Neurosurg. 2009;110(1): 156-162.
28. Pessina F, Navarria P, Cozzi L, et al. Value of surgical resection in patients with newly diagnosed grade III glioma treated in a multimodal approach: surgery, chemotherapy and radiotherapy. Ann Surg Oncol. 2016;23(9):3040-3046.

29. Beiko J, Suki D, Hess KR, et al. IDH1 mutant malignant astrocytomas are more amenable to surgical resection and have a survival benefit associated with maximal surgical resection. Neuro Oncol. 2014;16(1):81-91.

\section{Disclosures}

Dr. Santoro: consultant for Arqule and Sanofi; speakers bureau for Takeda, BMS, Roche, AbbVie, Amgen, Celgene, Servier, Gilead, AstraZeneca, Pfizer, Arqule, Lilly, Sandoz, Eisai, Novartis, Bayer, and MSD; and advisory board for BMS, Servier, Gilead, Pfizer, Eisai, Bayer, and MSD.

\section{Author Contributions}

Conception and design: Pessina, Navarria. Acquisition of data: Navarria, Clerici, Rossini, Franceschini, Lorenzi. Analysis and interpretation of data: Pessina, Navarria, Clerici, Rossini, Franceschini, D'Agostino, Politi, Grimaldi. Drafting the article: Pessina, Navarria. Critically revising the article: Pessina, Navarria, Franzese. Reviewed submitted version of manuscript: Pessina, Navarria, Loi. Approved the final version of the manuscript on behalf of all authors: Pessina. Statistical analysis: Pessina, Navarria, Clerici, D’Agostino, Franzese, Comito, Simonelli, Persico, Politi. Administrative/technical/material support: Rossini, Comito, Loi, Simonelli, Lorenzi, Persico. Study supervision: Pessina, Navarria, Bello, Santoro, Fornari, Servadei, Scorsetti.

\section{Correspondence}

Federico Pessina: Humanitas Cancer Center and Research Hospital, Rozzano, Italy. federico.pessina@hunimed.eu. 